\title{
Early diagnosis of enteromyxosis in intensively reared sharpsnout seabream, Diplodus puntazzo
}

\author{
Eleni GolOMAZOU ${ }^{\mathrm{a}}$, Athanasios EXADACTYLOS, Emmanouil E. MALANDRAKIS, Theodoros KaRATZINOS, \\ Georgios GKAFAS, Olga DADALI and Panagiota PANAGIOTAKI
}

Department of Ichthyology and Aquatic Environment, School of Agricultural Sciences, University of Thessaly, Fytokou str., 38445 Volos, Greece

Received 29 October 2014; Accepted 27 November 2014

\begin{abstract}
Myxozoans are metazoan parasites which are highly pathogenic in commercially important fish, particularly in aquaculture. Enteromyxosis is an economically significant disease caused by the myxosporean parasite Enteromyxum leei. Presently, early diagnosis of enteromyxosis in sharpsnout seabream was achieved by monitoring fish on a time-scale scheduled basis in combination with a validated molecular diagnostic technique. Two different successive fish batches of a commercial fish farm were monitored starting from the first month of on-growing in sea cages until fish reached commercial size. Fish weight and water temperature differentially ranged between them. E. leei detection was performed both by classical microscopic observation of fresh smears and by quantitative polymerase chain reaction (qPCR) while prevalence, mean intensity and mortality rate were calculated. In total, 520 fish were screened; 320 from the first batch and 200 from the second one. Parasitosis illustrated a seasonal occurrence pattern (spring and summer). When qPCR was used as a diagnostic method, enteromyxosis was diagnosed earlier with more increased prevalence compared to the microscopic observation. In this case, the parasite was detected at the lowest water temperature that has ever been recorded $\left(14.7^{\circ} \mathrm{C}\right)$, during the first month of on-growing in sea cages. The twofactor combination of water temperature and fish weight proved to be the most significant factor that could determine the emergence and development of parasitosis and smaller fish proved to be more susceptible. Mortality was influenced by both prevalence and intensity of parasitosis. An earlier diagnosis and identification of all developmental stages of the parasite throughout its life cycle was verified with qPCR, significantly before any outbreak occurred. The latter could become a key diagnostic tool for the control of enteromyxosis, allowing stakeholders and fish farmers to adopt all necessary precautionary measures minimizing economic loss in sharpsnout seabream intensive farming.
\end{abstract}

Keywords: Fish disease / Early diagnosis / Enteromyxosis / qPCR / Myxozoan parasites / Enteromyxum leei / Sparidae / Sharpsnout seabream

\section{Introduction}

Myxosporeans, being common parasites affecting intensively reared fish in the Mediterranean Sea, induce a broad spectrum of diseases depending on parasite species, host sensitivity, environmental and feeding conditions (Rigos et al. 1999; Kent et al. 2001; Golomazou et al. 2005; Palenzuela 2006; Rigos and Katharios 2010). Myxosporeans can parasitize in the skin or scales or they migrate and become coelozoic or histozoic. Most of them are not highly pathogenic for their hosts but in some cases, end in severe diseases causing substantial economic loss in aquaculture. Ceratomyxa, Henneguya, Myxobolus, Enteromyxum, Kudoa, Shaerospora, Polysporoplasma are some of the most common myxoporea

a Corresponding author: egolom@uth.gr genera which affect growth, fecundity and flesh quality. Their life cycle is complicated; for most species, life cycle is indirect involving an alternate host (invertebrates) where they develop actinospores, while in some cases of marine species direct transmission is reported (Gomez et al. 2014).

The myxosporean parasite Enteromyxum leei Diamant, Lom, Dyková, 1994, which is the causative agent of enteromyxosis, is an important pathogen of the Sparidae family, having a negative economic impact on fish farming in the Mediterranean Sea. It causes severe enteritis, anorexia, anaemia, emaciation, cachexia, all leading to death (Palenzuela 2006). The intestinal damage consists of vacuolation, necrosis, detachment and sloughing of epithelium (Alvarez-Pellitero et al. 2008) causing alterations in the intestinal mucous secretion (Estensoro et al. 2013). The parasite has been recorded in more than 49 fish species in the Mediterranean 
basin, the Red Sea and Japan and it has been reported as responsible for outbreaks in gilthead seabream Sparus aurata and sharpsnout seabream Diplodus puntazzo (Le Breton and Marques 1995; Sakiti et al. 1996; Padrós et al. 2001; Merrella et al. 2005; Montero et al. 2007; Sitjà-Bobadilla et al. 2007). Since 1995, when enteromyxosis was first reported in Greece, significant losses in cultured sharpsnout seabream have been recorded, raising questions about its viable farming (Le Breton and Marques 1995; Rigos et al. 1999; Rigos and Katharios 2010). According to FAO (2011), the world sharpsnout seabream production was dramatically reduced, during the last 10 years. Although Greece records a significant aquaculture production in gilthead seabream and European seabass Dicentrarchus labrax, it is not included in the FAO sharpsnout seabream producing countries list, since its low production is not worth mentioning. High mortalities of sharpsnout seabream due to enteromyxosis, are still reported in Greece (Rigos and Katharios 2010) indicating the sensitivity of this host (Munoz et al. 2007), thus this disease remains a significant threat for Mediterranean aquaculture.

Enteromyxosis is an easily spread but low progressive disease (Golomazou et al. 2006a, Sitjà-Bobadilla et al. 2007). This ease of transmission, in combination with the abundance of invertebrates and wild fish, which act as reservoirs of these myxosporeans, are also responsible for the spread of the disease under farmed conditions and hamper its prevention and control. Myxozoan infection depends on water temperature and enteromyxosis outbreaks have been reported at high water temperatures (Le Breton and Marques 1995; Golomazou et al. 2005; Palenzuela 2006; Yanagida et al. 2006), while low water temperature is considered as an inhibitory factor for the development of the disease (Estensoro et al. 2010).

The best approach in order to eliminate enteromyxosis could be its early diagnosis, a fact that remains critical for the control of this infectious disease. E. leei is usually detected by classical parasitogical diagnostic techniques, when the dissemination of the disease has been already occurred, causing high mortalities to infected fish. DNA-based assays have also been described for the detection of myxosporeans in fish including Enteromyxum species (Fox et al. 2000; Cavender et al. 2004; Kelley et al. 2004; Yanagida et al. 2005; Hallett and Bartholomew 2006; Sitjà-Bobadilla et al. 2007; Griffin et al. 2009; Estensoro et al. 2010; Hunt 2011; Piazzon et al. 2012; Alonso et al. 2014). However a robust validated molecular diagnostic technique, which could be applied for simultaneous detection and quantification of this parasite, has never been applied to date on any host species.

Therefore, the aim of the present study is to focus on the early diagnosis of enteromyxosis, which could be a useful tool for fish-farmers in order to take all necessary precautionary measures, before the outbreak occurs. For this reason, fish monitoring on a time-scale scheduled basis was performed and the appropriate timing for achieving an early diagnosis was defined. Moreover, water temperature fluctuation and fish weight contributing to E. leei detection and development during early stages was discussed. qPCR was the molecular tool used for E. leei detection and its subsequent quantification, identifying all developmental stages of the parasite throughout its life cycle without differentiating them.

\section{Materials and methods}

\subsection{Fish and sampling procedure}

Sharpsnout seabream specimens were sampled from sea cages of a commercial fish farm, where enteromyxosis has been diagnosed in the past, showing clinical signs (acute enteritis, anorexia, extensive emaciation) and high mortality rate. Monitoring of the sharpsnout seabream farm on a time-scale scheduled basis started from the first month of on-growing in sea cages. Sampling schedule was set on a monthly basis and was carried out during the last week of each month, until fish recovered from enteromyxosis. From this point onwards, samplings were carried out during the last month of each season until fish reached the commercial size (two samplings for year class 2008-2010 and three samplings for year class 2010-2011), since no infection was expected. Two different successive fish batches were monitored (year class 2008-2010 and 2010-2011) while fish weight ranged between them. For the first batch monthly samplings started in September 2008 (fish mean weight: $2.1 \pm 0.3 \mathrm{~g}$ ) and lasted until September 2009 (fish mean weight: $139.6 \pm 5.2 \mathrm{~g}$ ), while for the second batch monthly samplings started in March 2010 (fish mean weight: $2.1 \pm 0.2 \mathrm{~g}$ ) and lasted until September 2010 (fish mean weight: $34.7 \pm 3.3 \mathrm{~g}$ ). Sampling detailed protocol is described in Table 1.

Enteromyxum leei diagnosis was performed by classical microscopic observation of fresh smears and by qPCR (as described below). The prevalence and mean intensity of infection at each sampling date were calculated separately for both applied techniques. Fish weight and mortality, along with water temperature were recorded periodically.

Before experimental samplings, 20 fish from the hatchery were screened to ensure the absence of pathogens in experimental fish. Bacteriological and parasitological examinations (as described below) were included in the presampling testing. Additionally, qPCR was applied in a tissue portion taken from the posterior intestine, to ensure the absence of early stages of E. leei that could not be detected by microscopic observation of intestine smears. 520 specimens were screened in total using classical microscopic observation of fresh intestine smears and qPCR.

\subsection{Bacteriological examination}

Fish were killed by overdose of anesthetic (MS222) and kidney and spleen samples were inoculated onto Tryptone Soy Agar (TSA) and Thiosulphate Citrate Bile Salt Agar (TCBS) for bacteriology according to methods described by Roberts and Shepherd (1997).

\subsection{Microscopic observation of fresh smears}

After fish were killed by overdose of anesthetic (MS222), fresh scrapings and smears of internal organs (posterior intestine, gallbladder, kidney, liver, spleen and heart) and gills, were examined at each sampled fish, according to methods described by Roberts (1989). 100 random viewing fields per slide (magnification, $\times 400$ ) were counted for each sample. The prevalence of infection was assessed for each sampling month. 
Table 1. Monthly sampling protocol from the first month of on-growing in sea cages until fish recover from enteromyxosis. Mean fish weight, mean water temperature and mortality rate are presented for two different successive fish batches (year classes 2008-2010, 2010-2011).

\begin{tabular}{|c|c|c|c|c|c|c|c|c|c|c|c|c|c|c|}
\hline & $\begin{array}{l}\text { EXIT from } \\
\text { hatchery }\end{array}$ & \multicolumn{13}{|c|}{ Monthly sampling dates } \\
\hline $\begin{array}{c}\text { Batch I } \\
\text { Year class }\end{array}$ & $\begin{array}{c}\text { Early Sept. } \\
2008\end{array}$ & Sept. & Oct. & Nov. & Dec. & Jan. & Feb. & Mar. & Apr. & May & June & July & Aug. & Sept. \\
\hline $2008-2010$ & \multicolumn{6}{|c|}{2008} & \multicolumn{8}{|c|}{2009} \\
\hline$N$ & 20 & 20 & 20 & 20 & 20 & 20 & 20 & 20 & 20 & 20 & 20 & 20 & 20 & 20 \\
\hline Mean weight (g) & 2.11 & 3.08 & 7.58 & 12.6 & 13.01 & 16.7 & 18.9 & 21.6 & 27.4 & 37.5 & 54.1 & 77.2 & 100.4 & 139.6 \\
\hline & \pm 0.3 & \pm 0.5 & \pm 0.8 & \pm 0.9 & \pm 0.8 & \pm 1.1 & \pm 1.5 & \pm 1.9 & \pm 3.4 & \pm 2.8 & \pm 3.8 & \pm 4.5 & \pm 4.9 & \pm 5.2 \\
\hline Mean water & 24.3 & 23.7 & 22.3 & 20 & 16.1 & 15 & 14.5 & 14.2 & 16.7 & 20.5 & 22 & 22 & 27 & 24 \\
\hline temperature $\left({ }^{\circ} \mathrm{C}\right)$ & \pm 0.1 & \pm 0.2 & \pm 0.4 & \pm 0.2 & \pm 0.3 & \pm 0.2 & \pm 0.2 & \pm 0.1 & \pm 0.2 & \pm 0.2 & \pm 0.2 & \pm 0.4 & \pm 0.2 & \pm 0.2 \\
\hline Mortality rate $(\%)$ & & nwm & nwm & nwm & nwm & nwm & nwm & nwm & nwm & nwm & nwm & nwm & nwm & nwm \\
\hline Batch II & Mar. 2010 & & & & & & & & Apr. & May & June & July & Aug. & Sept. \\
\hline Year class & & & & & & & & & 2010 & 2010 & 2010 & 2010 & 2010 & 2010 \\
\hline $2010-2011$ & & & & & & & & & & & & & & \\
\hline$N$ & 20 & & & & & & & & 20 & 20 & 20 & 20 & 20 & 20 \\
\hline Mean weight (g) & 2.1 & & & & & & & & 2.4 & 4.9 & 11.2 & 21.7 & 26.8 & 34.7 \\
\hline & \pm 0.2 & & & & & & & & \pm 0.2 & \pm 0.4 & \pm 0.7 & \pm 1.3 & \pm 2.1 & \pm 3.3 \\
\hline Mean water & 13.4 & & & & & & & & 14.8 & 17.2 & 20 & 24 & 25.5 & 22 \\
\hline temperature $\left({ }^{\circ} \mathrm{C}\right)$ & \pm 0.1 & & & & & & & & \pm 0.2 & \pm 0.2 & \pm 0.2 & \pm 0.2 & \pm 0.2 & \pm 0.3 \\
\hline Mortality rate (\%) & & & & & & & & & nwm & nwm & nwm & 2 & 19 & nwm \\
\hline
\end{tabular}

nwm: not worth mentioning.

Parasite identification was carried out according to Yamaguti (1963). The intensity of E. leei infection was estimated by the number of myxosporeans counted per viewing field.

\subsection{DNA extraction and standard curve construction for absolute quantification}

DNA from the posterior intestine was extracted with a phenol-chloroform protocol (Sambrook et al. 1989) with minor modifications. Primers (EL1F: ACCAAGTCTTCGGGCTCTG and EL2R: TCTGTCATTCTGTCAATCCTATCG) were specially designed to anneal to the $18 \mathrm{~S}$ small subunit ribosomal RNA gene of E. leei (GenBank accession no. AY520574). These primers were targeted solely for specific detection of $E$. leei rather than other Enteromyxum species. PCR products were gel purified, ligated in a pCR $^{\circledR} 4-\mathrm{TOPO}^{\circledR}$ vector, transformed in TOP10 electrocompetent cells (Invitrogen) and sequenced with the M13 forward primer (Macrogen, Korea). The extracted plasmids (NucleoSpin Plasmid, Macherey-Nagel, Duren, Germany) were used as standards for absolute quantification. Eight serial dilutions (10-fold) were used with concentrations ranging from 2 to $2 \times 10^{7}$ copies of plasmid DNA. Plasmid copy numbers were calculated taking into account concentration, molecular mass and Avogadro's constant.

\subsection{Absolute quantification of $E$. leei copy numbers}

qPCR reactions were performed in technical triplicates containing $5 \mu \mathrm{l}\left(20 \mathrm{ng} \mu \mathrm{l}^{-1}\right.$ total DNA) of template DNA, $1 \mu \mathrm{M}$ of each primer and $12.5 \mu \mathrm{l}$ of SybrGreener ${ }^{\circledR}$ qPCR Supermix Universal (Invitrogen) up to a final volume of $25 \mu \mathrm{l}$. qPCR conditions consisted of an initial denaturation step of $95{ }^{\circ} \mathrm{C}$ for $10 \mathrm{~min}$, followed by 40 cycles of $95{ }^{\circ} \mathrm{C}$ for $15 \mathrm{~s}$ and $60{ }^{\circ} \mathrm{C}$ for $45 \mathrm{~s}$. Reactions were carried out in an $\mathrm{MJ}$
Research Chromo4 Real-time PCR cycler (BioRad, Hercules, CA, USA). Products demonstrated uniform melting curves and randomly chosen ones were sequenced. No template reactions were used as negative controls. Quantification cycles (Cq) were extracted using the Opticon Monitor 3 software (BioRad). Copy numbers were intrapolated from the standard curve plotted with plasmid concentrations over quantification cycles. E. leei intensity was calculated as $18 \mathrm{~S}$ copy number per $100 \mathrm{ng}$ of total intestine DNA for each sample. The detection limit of the assay was as low as 2 copies of $18 \mathrm{~S}$ SSU ribosomal DNA per sample.

\subsection{Statistical analysis}

Contingency tables were conducted using the RxC software running 20 groups and 2500 replicates per group (Miller 1997). RxC employs the metropolis algorithm to obtain an unbiased estimate of the exact $p$ value. Contingency tables were used to compare prevalence, intensity and mortality rate, among the two different batches (2008-2010 and 2010-2011). Calculations were performed against the different months for the total number of individuals and against different condition factors (fish weight and water temperature) and their combination. Bonferroni corrections were calculated to deal with false discovery due to type I errors.

\section{Results}

\subsection{Prevalence}

Enteromyxum leei mature spores were detected only in the intestine of examined fish. According to microscopic observation of fresh intestine smears, E. leei was detected for the first time during May 2009 with $10 \%$ prevalence. During June 2009, prevalence was reduced to $5 \%$, while the parasite was not detected thereafter. During the monitoring of the 


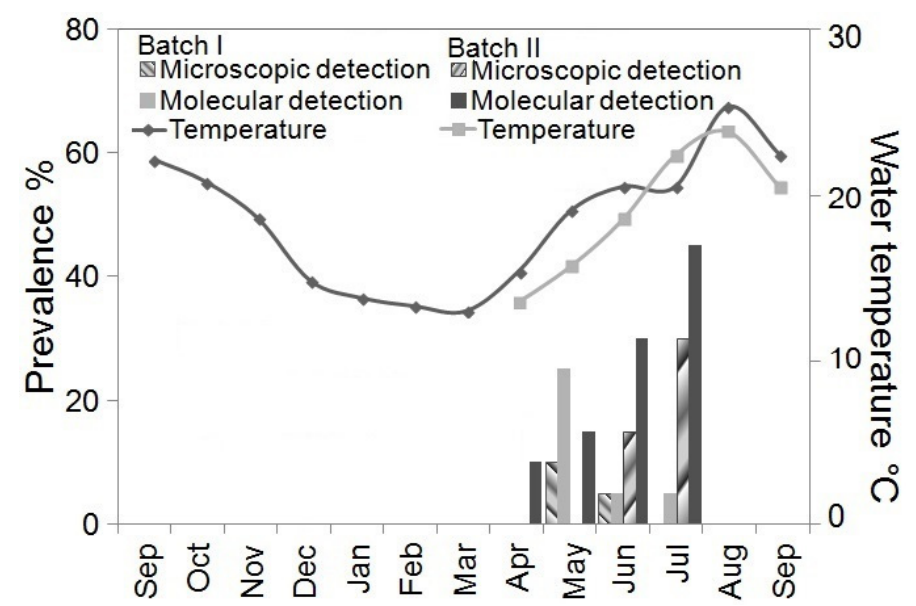

Fig. 1. Prevalence fluctuation based on diagnostic results of microscopic observation of fresh intestine smears and qPCR. Monthly samplings are presented from September 2008 to 2009 and from April to September 2010 for the two examined year classes (2008-2010, 2010-2011), respectively. 320 fish were screened from the first batch and 200 from the second one. When qPCR was used as a diagnostic method, enteromyxosis was diagnosed earlier with more increased prevalence compared to the microscopic observation. Seawater temperature profile is presented.

Table 2. Monthly contingency table for the two year classes (2008-2010, 2010-2011) when enteromyxosis was diagnosed, $p$ values indicate high significances for both weight $\&$ temperature at $p_{99}$ criterion.

\begin{tabular}{cccccccc}
\hline & & \multicolumn{3}{c}{ Prevalence } & \multicolumn{3}{c}{ Intensity } \\
\hline Months & Condition & $x^{2}$ & $d f$ & $p$-value & $x^{2}$ & $d f$ & $p$-value \\
\hline \multirow{4}{*}{ April } & Weight & 17.7 & 2 & $<0.001$ & 89.88 & 2 & $<0.001$ \\
& Temperature & 2.12 & 2 & $\mathrm{~ns}$ & 45.39 & 2 & $<0.001$ \\
& Weight \& & 18.51 & 3 & $<0.001$ & 86.75 & 3 & $<0.001$ \\
& Temperature & & & & & & \\
& Weight & 14.66 & 2 & $<0.001$ & 4.55 & 2 & $\mathrm{~ns}$ \\
May & Temperature & 0.48 & 2 & $\mathrm{~ns}$ & 29.4 & 2 & $<0.001$ \\
& Weight \& & 16.2 & 3 & $<0.001$ & 31.33 & 3 & $<0.001$ \\
& Temperature & & & & & & \\
& Weight & 21.47 & 2 & $<0.001$ & 364.12 & 2 & $<0.001$ \\
June & Temperature & 3.51 & 2 & ns & 119.7 & 2 & $<0.001$ \\
& Weight \& & 23.31 & 3 & $<0.001$ & 379.92 & 3 & $<0.001$ \\
& Temperature & & & & & & \\
& Weight & 25.09 & 2 & $<0.001$ & 125.35 & 2 & $<0.001$ \\
July & Temperature & 5.51 & 2 & ns & 27.25 & 2 & $<0.001$ \\
& Weight \& & 28.73 & 3 & $<0.001$ & 125.77 & 3 & $<0.001$ \\
& Temperature & & & & & & \\
\hline
\end{tabular}

ns: non significant.

second batch, infected fish were firstly diagnosed during June 2010 with $15 \%$ prevalence, while the highest prevalence was recorded during July (30\%), which was the last month that the parasite was detected (Fig. 1).

When qPCR was used as a diagnostic method, E. leei was detected earlier and with more increased prevalence compared to the microscopic observation. In the first batch, the parasite was detected during May 2009 with 25\% prevalence, which was gradually reduced to $5 \%$ during June and July. For the second batch, the parasite was detected even earlier, compared to the previous year class, during April 2010 (10\%) while prevalence was gradually increased during May (15\%), June (30\%) and July (45\%). For both examined year classes the parasite was not detected thereafter (Fig. 1). A contingency table concerning the prevalence of the two examined year classes re- vealed that the two-factor combination of water temperature and fish weight is an important parameter that can influence parasitosis (Table 2).

\subsection{Intensity}

According to microscopic observation of fresh intestine smears, E. leei was detected at low mean intensity for all examined cases. All developmental stages were counted, with mature spores being the predominant stage. During the monitoring of the first batch, mean intensity ranged from $0.4 \pm 0.1$ to 0.2 parasites/viewing field during May and June, respectively. For the second batch, mean intensity ranged from $1 \pm 0.15$ to $0.2 \pm 0.05$ parasites/viewing field during June and July respectively (Fig. 2a). When qPCR was used as a diagnostic method 


\section{(a) microscopic detection}

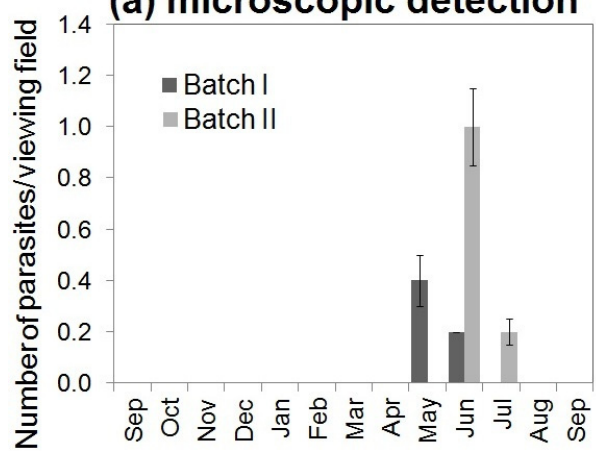

(b) molecular detection

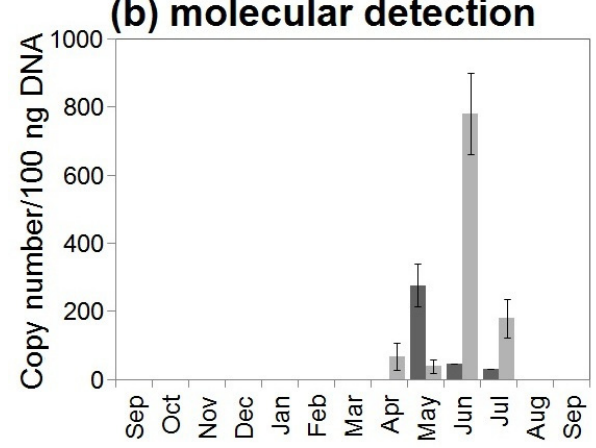

Fig. 2. Intensity fluctuation based on diagnostic results of microscopic observation of fresh intestine smears (a) and qPCR (b). Monthly samplings are presented from September 2008 to 2009 and from April to September 2010 for the two examined year classes (2008-2010, 2010-2011), respectively. Number of parasites (mean \pm SD) detected per viewing field after microscopic observation is presented. 100 random viewing fields per slide (magnification, $\times 400$ ) were counted for each sample. In case that qPCR was used as diagnostic method, E. leei intensity was calculated as $18 \mathrm{~S}$ copy number per $100 \mathrm{ng}$ of total intestine DNA for each sample.

for the first year class, the highest mean intensity of parasitosis was $276 \pm 63$ copies/ 100 ng DNA during May. As far as the second batch, the highest mean intensity of parasitosis was recorded during June ( $781 \pm 120$ copies/100 ng DNA). Consistently after July the parasite was not detected for both examined fish batches (Fig. 2b). Once more the two-factor combination of water temperature and fish weight influenced significantly the development of the parasite in the host. The striking pattern is that significantly smaller fish of the second batch are more sensitive to enteromyxosis concerning both prevalence and intensity (Table 2).

\subsection{Mortality rate}

Mortalities were not worth mentioning, despite the fact that the parasite was detected in the first fish batch. For the second batch, where enteromyxosis was comparatively more severe, significant mortalities were recorded (Table 1). The mortality rate was significantly increased from $2 \%$ to $19 \%$ during August $(p<0.001)$, when the highest water temperature was also recorded (Fig. 3). Moreover, significances were revealed from the obtained data, where mortality rate was influenced by both prevalence $(p<0.001)$ and intensity $(p<0.001)$ of parasitosis.

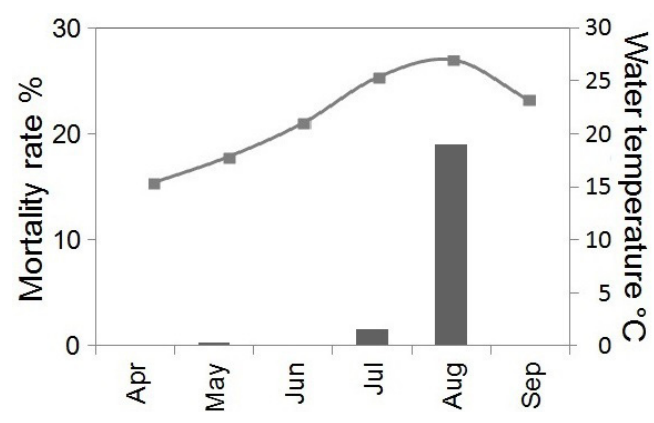

Fig. 3. Mortality rate during the monitoring of the second batch. Temperature profile is presented showing that the highest water temperature and mortality rate were recorded during August.

\section{Discussion}

Enteromyxosis, is an important infectious disease with negative economic impact on fish farming throughout the Mediterranean Sea, since intensively reared Mediterranean fish are included between the most important hosts. In the present study, monitoring of a sharpsnout seabream farm on a time-scale scheduled basis took place in order to achieve early diagnosis of enteromyxosis due to Enteromyxum leei. For this reason, fish were examined on a monthly basis after their exit from the hatchery, in order early developmental stages of the parasite to be detected. It was confirmed from the obtained data that in case of sharpsnout seabream, enteromyxosis illustrated a seasonal occurrence; the parasite was detected during spring and summer evidently. Maximum levels of prevalence, intensity and mortality rate were observed when water temperature was recorded at $>20^{\circ} \mathrm{C}$. This seasonal detection was expected as the development of enteromyxosis is closely influenced by water temperature and outbreaks have been reported from $18{ }^{\circ} \mathrm{C}$ to $22^{\circ} \mathrm{C}$ (Le Breton and Marques 1995; Rigos et al. 1999; Fleurance et al. 2008).

Noteworthy is the fact that the parasite was detected at low prevalence and intensity when water temperature was recorded as low as $14.7{ }^{\circ} \mathrm{C}$, during the first month of ongrowing in sea cages. This is the lowest temperature that has ever been recorded for E. leei detection, as in other cases the onset of the disease was suppressed by low water temperatures $\left(<15{ }^{\circ} \mathrm{C}\right)$ (Yanagida et al. 2006). It has been claimed that during cold seasons, parasites probably become latent, but they have the capability of re-emergence when water temperature is increased. Arrested development, or latency in the host at low water temperatures is probably the explanation for infected fish in such cases (Olson 1981), while the infective dose in the water during winter is not enough to establish successfully the infection (Alama-Bermejo et al. 2013), as in case of the present study. Mature spores can survive in seawater during cold seasons, while parasite's viability may be supported by several parameters, such as its localization in intestinal mucosal remnants and its ability to remain infectious despite temperature and salinity fluctuations (Ibarra et al. 1992; Yokoyama and Urawa 1997; Estensoro et al. 2010).

It was confirmed from the obtained data that the initial stage of the infection is deemed as the most critical point for its development and control. Although the parasite exists in sea water in latency, its transmission to uninfected fish may begin 
in a short time period, low progressing thereafter, without obvious occurrence of significant mortality rate (Golomazou et al. 2006a). The latter explains the fact that the parasite was detected even from the first month (April) of on-growing in sea cages for the smaller fish. During this crucial time period, prevalence and intensity may be subsequently increased by the intake of new parasite infectious stages through waterborne contamination and through autoinfection, always when conditions favours its development (Golomazou et al. 2006a).

The two-factor combination of water temperature and fish weight proved to be the most considerable factor that could determine the emergence and development of parasitosis. During the monitoring of the first batch the development of enteromyxosis declined without record of worth mentioning mortalities. This could be explained by the unusual water temperature fluctuation during that period, a fact that probably interrupted the development of parasitic infectious stages, confirming the strong correlation between intensity and water temperature. Moreover, fish weight was proved to be an equally important factor that could influence the emergence, the development of parasitosis and the immune fish response. Indeed, fish from the first batch were considerably larger than those from the second one when they were introduced to the likely infected habitat (sea cages). However, water temperature profile for the first batch was not favourable for an outburst, unlike temperature profile for the second one. It is well known that fish size influences immune response and more competent immune response is expected in larger fish of the same age (Johnson et al. 1982), while in younger fish immune organs are less developed compared to elder ones and progressive cell differentiation and maturation are achieved over time (Gradil et al. 2014).

Myxosporeans, as other parasites, are usually detected using classical parasitological techniques such as microscopic examination of fresh smears and standard histological techniques. In such cases, fish are considered to be infected only if trophozoites or mature spores are observed in tissue scrapings and if clear histological evidence of the parasite infection is subsequently demonstrated, while parasite proliferative infectious stages cannot be detected, thus preventing early diagnosis. PCR-based DNA-detection techniques have been described to date for the detection of intestinal parasites including Enteromyxum species showing higher sensitivity and specificity compared to microscopy (Bretagne and Costa 2006; Sitjà-Bobadilla et al. 2007; Murray and Cappello 2008; Van Lieshout and Verweij 2010, Hunt 2011; Piazzon et al. 2012; Alonso et al. 2014), but qPCR for an early detection and quantification of this parasite has never been applied to date. Presently, qPCR was used allowing earlier diagnosis and identification of all developmental stages of the parasite throughout its life cycle, significantly before any outbreak occurred, thus combining parasitosis' prevalence and intensity.

Enteromyxosis is a disease with severe consequences all leading to death. Considering mortality as a disease severity index, it ensues that consequences of enteromyxosis can be mitigated. Presently, the mortality rate was influenced by the difference in prevalence and development of parasitosis between the two examined fish batches. Mortality rate was increased significantly during August, when the development of all in- fectious parasitic stages was completed and the highest mean water temperature was also recorded. By the time parasitosis recorded its highest pick, the parasite was not detected thereafter. This is probably due to the fact that monthly samplings were carried out during the last week of each month, when most of the infected fish had already died. Moreover, infected fish that survived through parasitosis developed self-recovery immune mechanisms preventing reinfection while the parasite was easily rejected since located in the intestine. Recovery mechanisms of infected fish have been reported in case of enteromyxosis (Golomazou et al. 2006a, b; Yanagida et al. 2006; Estensoro et al. 2010) and the ability of fish to recover successfully from E. leei infection could be partly related to certain immune response mechanisms such as the capacity of the organism to restore peroxidases to preinfection levels (Munoz et al. 2007). Furthermore, the cellular response of infected fish is activated involving elements of innate and adaptive immunity (Estensoro et al. 2014; Davey et al. 2011).

Sharpsnout seabream seems to be a sensitive host to enteromyxosis due to parasite E. leei. Its commercial value creates the need for appropriate health management based primarily on early diagnosis. Some of the most strategic steps for the adoption of a successful approach to early diagnosis are: (i) the comprehension of the significance of water temperature fluctuation and fish size class contributing to E. leei development during early stages, the importance of monitoring of sharpsnout seabream farms on a time-scale scheduled basis in combination with the appropriate timing of an early diagnosis and finally the development of a robust validated diagnostic technique for $E$. leei early detection and quantification (qPCR assay).

\section{Conclusion}

Enteromyxosis is an easily spread, low progressive disease and important threat for Mediterranean aquaculture. The parasite has been recorded in a lot of fish species but significant mortalities in cultured sharpsnout seabream, have raised questions about its viable farming. It was proved from the present study that fish monitoring on a time-scale scheduled basis favours early diagnosis, before the outbreak occurs. First contact of fish with the pathogen seems to be of great importance and happens when fish are introduced to sea cages, even in low water temperature, as the parasite may be in a latent condition. This fact in combination with water temperature profile and fish weight can determine the intense development of parasitosis and the expected mortality rate. Furthermore, the ability of fish to adopt specific immune response after the contact with the parasite preventing reinfection, was confirmed since the parasite was not detected from its outburst onward. Thus, illustration of autoimmunization mechanisms could be a useful tool in order to control enteroxyxosis, mitigating the consequences from the lack of vaccination. Moreover, the application of qPCR which is a sensitive, specific and rapid assay combining parasitosis' prevalence and intensity, proved to be necessary in order to achieve Enteromyxum leei detection of all developmental stages of the parasite, significantly before any outbreak occurs. In summary, early diagnosis in combination with a validated molecular diagnostic technique could become 
the key tool for the control of enteromyxosis, allowing stakeholders and fish farmers to adopt all necessary precautionary measures minimizing economic loss in sharpsnout seabream intensive farming.

\section{References}

Alama-Bermejo G., Šíma R., Raga J.A., Holzer A.S., 2013, Understanding myxozoan infection dynamics in the sea: Seasonality and transmission of Ceratomyxa puntazzi. Int. J. Parasitol. 43, 771-780.

Alonso M., Lago F.M., Gómez-Reino M., Fernández Casal J., Martín Varela I., Vieites J.M., Espineira M., 2014, Non-invasive fast real-time PCR assay for detection of the enteric parasite Enteromyxum scophthalmi in cultured turbot (Scophthalmus maximus L.) Aquac. Res. 1-12.

Álvarez-Pellitero P., Palenzuela O., Sitjà-Bobadilla A., 2008, Histopathology and cellular response in Enteromyxum leei (Myxozoa) infections of Diplodus puntazzo (Teleostei). Parasitol. Int. 57, 110-120.

Bretagne S., Costa J., 2006, Towards a nucleic acid-based diagnosis in clinical parasitology and mycology. Clin. Chim. Acta 363, 221-228.

Cavender W.P., Wood J.S., Powell M.S., Overturf K., Cain K.D., 2004, Real-time quantitative polymerase chain reaction (QPCR) to identify Myxobolus cerebralis in rainbow trout Oncorhynchus mykiss. Dis. Aquat. Org. 60, 205-213.

Diamant A., 1998, Red drum Sciaenops ocellatus (Sciaenidae), a recent introduction to Mediterranean mariculture, is susceptible to Myxidium leei (Myxosporea). Aquaculture 162, 33-39.

Diamant A., Ram S., Paperna I., 2006, Experimental transmission of Enteromyxum leei to freshwater fish. Dis. Aquat. Org. 72, 171-178.

Davey G.C., Calduch-Giner J.A., Houeix B., Talbot A., Prunet P., Pérez-Sánchez J., Cairns M.T., 2011, Molecular profiling of the gilthead sea bream (Sparus aurata L.) response to chronic exposure to the myxosporean parasite Enteromyxum leei. Mol. Immunol. 48, 2102-2112.

Estensoro I.M., Redondo J., Alvarez-Pellitero P., Sitjà-Bobadilla A., 2010, Novel horizontal transmission route for Enteromyxum leei (Myxozoa) by anal intubation of gilthead sea bream Sparus aurata. Dis. Aquat. Org. 92, 51-58.

Estensoro I., Jung-Schroers V., Álvarez-Pellitero P., Steinhagen D., Sitjà-Bobadilla A., 2013, Effects of Enteromyxum leei (Myxozoa) infection on gilthead sea bream (Sparus aurata) (Teleostei) intestinal mucus: Glycoprotein profile and bacterial adhesion. Parasitol. Res. 112, 567-576.

Estensoro I., Mulero I., Redondo M., Álvarez-Pellitero P., Mulero V., Sitjà-Bobadilla A., 2014, Modulation of leukocytic populations of gilthead sea bream (Sparus aurata) by the intestinal parasite Enteromyxum leei (Myxozoa: Myxosporea). Parasitology 141, 425-440.

FAO, Food and Agriculture Organization of the United Nations, 2011, Fishery and Aquaculture Statistics, Aquaculture Production 2009.

Fleurance R., Sauvegrain C., Marques A., Le Breton A., Guereaud C., Cherel Y., Wyers M., 2008, Histopathological changes caused by Enteromyxum leei infection in farmed sea bream Sparus aurata. Dis. Aquat. Org. 79, 219-228.
Fox M.D., Palenzuela O., Bartholomew J.L., 2000, Strategies for the diagnosis of Ceratomyxa shasta using the polymerase chain reaction: Comparison of lethal and nonlethal sampling with microscopic examination. J. Aquat. Anim. Health 12, 100-106.

Golomazou E., Karagouni E., Athanassopoulou F., 2005, The most important Myxosporean parasite species affecting cultured Mediterranean fish. J. Hell. Vet. Med. Soc. 55, 342-352.

Golomazou E., Athanassopoulou F., Karagouni E., Tsagozis P., Tsantilas H., Vagianou S., 2006a, Experimental transmission of Enteromyxum leei Diamant, Lom and Dykova, 1994 in sharpsnout sea bream, Diplodus puntazzo C. and the effect on some innate immune parameters. Aquaculture 260, 44-53.

Golomazou E., Athanassopoulou F., Karagouni E., Vagianou S., Tsantilas H., Karamanis D., 2006b, Efficacy and toxicity of orally administrated anti-coccidial drug treatment on Enteromyxum leei infections in sharpsnout seabream (Diplodus puntazzo C.). Isr. J. Aquac. Bamidgeh 58, 157-169.

Gómez D., Bartholomew J., Sunyer J.O., 2014, Biology and mucosal immunity to myxozoans. Dev. Comp. Immunol. 43, 243-256.

Gradil M.A., Wright M.G., Wadowska W.D., Fast D.M., 2014, Ontogeny of the immune system in Acipenserid juveniles. Dev. Comp. Immunol. 44, 303-314.

Griffin M.J., Pote L.M., Camus A.C., Mauel M.J., Greenway T.E., Wise D.J., 2009, Application of a real-time PCR assay for the detection of Henneguya ictaluri in commercial channel catfish ponds. Dis. Aquat. Org. 86, 223-233.

Hallett S.L., Bartholomew J.L., 2006, Application of a real-time PCR assay to detect and quantify the myxozoan parasite Ceratomyxa shasta in river water samples. Dis. Aquat. Org. 71, 109-118.

Hunt P.W., 2011, Molecular diagnosis of infections and resistance in veterinary and human parasites. Vet. Parasitol. 180, 12-46.

Ibarra A.M., Hedrick R.P., Gall G.A.E., 1992, Inheritance of susceptibility to Ceratomyxa shasta (Myxozoa) in rainbow trout and the effect of length of exposure on the liability to develop ceratomyxosis. Aquaculture 104, 217-229.

Johnson K.A., Flynn J.K., Amend D.F., 1982, Onset of immunity in salmonid fry vaccinated by direct immersion in Vibrio anguillarum and Yersinia ruckeri bacterins. J. Fish Dis. 5, 197-205.

Katharios P., Rigos G., Divanach P., 2011, Enteromyxum leei (Myxozoa), a lethal intruder of tropical pet fish: First case in humphead wrasse, Cheilinus undulatus (Rüppell, 1835). J. Exotic Pet Med. 20, 138-143.

Katharios P., Kokkari C., Sterioti A., Smyrli M., Kalatzis G.P., 2014, Enteromyxum leei infection in parrotfish, Sparisoma cretense: Histopathological, morphological and molecular study. Vet. Parasitol. 199, 136-143.

Kelley G.O., Zagmutt-Vergara F.J., Leutenegger C.M., Myklebust K.A., Adkison M.A., McDowell T.S., Marty G.D., Kahler A.L., Bush A.L., Gardner I.A., Hedrick R.P., 2004, Evaluation of five diagnostic methods for the detection and quantification of Myxobolus cerebralis. J. Vet. Diagn. Invest. 16, 202-211.

Kent M., Andree K.B., Bartholomew J.L., El-Matbouli M., Desser S.S., Devlin R.H., Feist S.W., Hallet S.L., Hedrick R.P., Hoffmann R.W., Khattra J., Lester R.J.G., Longshaw M., Palenzuela O., Xiao L., 2001, Recent advances in our knowledge of Myxozoa. J. Eukaryot. Microbiol. 48, 395-413.

Le Breton A., Marques A., 1995, Occurrence of an histozoic Myxidium infection in two marine culture species: Puntazzo puntazzo C. and Pagrus major. Bull. Eur. Assoc. Fish Pathol. 15, 210-212. 
Merella P., Cherchi S., Salati F., Garippa G., 2005, Parasitological survey of sharpsnout seabream Diplodus puntazzo (Cetti, 1777) reared in sea cages in Sardinia (western Mediterranean). Bull. Eur. Assoc. Fish Pathol. 25, 140-147.

Miller M., 1997, RxC, a program for the analysis of contingency tables. Department of Biological Sciences, Northern Arizona University.

Montero F., Cuadrado M., Padros F., Crespo S., Raga J.A., 2007, Cryptocaryon irritans and Enteromyxum leei, two threats for the culture of Diplodus puntazzo in the Mediterranean. Bull. Eur. Assoc. Fish Pathol. 27, 242-247.

Muñoz P., Cuesta A., Athanassopoulou F., Golomazou H., Crespo S., Padrós F., Sitjà-Bobadilla A., Albiñana G., Esteban M.A., Alvarez-Pellitero P., Meseguer J., 2007, Sharpsnout sea bream (Diplodus puntazzo) humoral immune response against the parasite Enteromyxum leei (Myxozoa). Fish Shellfish Immunol. 23, 636-645.

Murray T.S., Cappello M., 2008, The molecular diagnosis of parasitic diseases. Pediatr. Infect. Dis. J. 27(2), 163-164.

Olson R.E., 1981, Effects of low temperature on the development of the microsporidian Glugea stephani in English sole (Parophrys vetulus). J. Wildlife Dis. 17, 559-562.

Padros F., Palenzuela O., Hispano C., Tosas O., Zarza C., Crespo S., Alvarez-Pellitero P., 2001, Myxidium leei (Myxozoa) infections in aquarium-reared Mediterranean fish species. Dis. Aquat. Org. $47,57-62$.

Palenzuela O., 2006, Mixozoan infections in Mediterranean mariculture. Parassitologia 48, 27-29.

Piazzon C., Mallo N., Martin I., Fernandez-Casal J., Sanmartin M.L., Lamas J., Leiro J.M., 2012, Development of a real-time PCR assay for detection and quantification of Enteromyxum scophthalmi parasites in turbot intestinal samples. Aquaculture 366-367, 122-128.

Rigos G., Katharios P., 2010, Pathological obstacles of newly introduced fish species in Mediterranean mariculture: a review. Rev. Fish Biol. Fish. 20, 47-70.
Rigos G., Christophilogiannis P., Yiagnisi M., Andriopoulou A., Koutsodimou M., Nengas I., Alexis M., 1999, Myxosporean infections in Greek mariculture. Aquac. Int. 7, 361-364.

Roberts R.J., 1989, Fish pathology. Bailliere, Tindall, London.

Roberts R.J., Shepherd C.J., 1997, Handbook of trout and salmon diseases. Fishing News Books, Oxford.

Sakiti P.N., Tarer V., Jacquemin D., Marques A., 1996, Présence en Méditerranée occidentale d'une Myxosporidie histozoïque pathogène dans les élevages de daurade, Sparus aurata L. Ann. Sci. Nat. Zool. Paris 17, 123-127.

Sambrook J., Fritsch E.F., Maniatis T., 1989, Molecular Cloning: A Laboratory Manual, second ed. vol. 3. Cold Spring Harbor Laboratory Press.

Sitjà-Bobadilla A., Diamant A., Palenzuela O., Álvarez-Pellitero P., 2007, Host factors and experimental conditions on the horizontal transmission of Enteromyxym leei (Myxozoa) to gilthead sea bream (Sparus aurata L.) and European sea bass (Dicentrarchus labrax L.). J. Fish Dis. 29, 1-8.

Van Lieshout L., Verweij J.J., 2010, Newer diagnostic approaches to intestinal protozoa. Curr. Opin. Infect. Dis. 23, 488-493.

Yamaguti S., 1963, Systema Helminthum Vol. I-II. Interscience Publishers, New York.

Yanagida T., Freeman M.A., Nomura Y., Takami I., Sugihara Y., Yokoyama H., Ogawa K., 2005, Development of a PCR-based method for the detection of enteric myxozoans causing the emaciation disease of cultured tiger puffer. Fish Pathol. 40, 22-28.

Yanagida T., Sameshima M., Nasu H., Yokoyama H., Ogawa K., 2006, Temperature effects on the development of Enteromyxum spp. (Мyхоzoa) in experimentally infected tiger puffer, Takifugu rubripes (Temmink \& Schlegel). J. Fish Dis. 29, 561-567.

Yasuda H., Ooyama T., Nakamura A., Iwata K., Palenzuela O., Yokoyama H., 2005, Occurrence of the myxosporean emaciation disease caused by Enteromyxum leei in cultured Japanese flounder Paralichthys olivaceus. Fish Pathol. 40, 175-180.

Yokoyama H., Urawa S., 1997, Fluorescent labelling of actinospores for determining the portals of entry into fish. Dis. Aquat. Org. 30, 165-169. 